\title{
Formulation and Evaluation of Controlled Release Gastro-Retentive In situ Gel for Diltiazem Hydrochloride
}

\author{
Nishan Naresh Bobade and Shrikant Devidas Pande \\ Vidyabharati College of Pharmacy, C. K. Naidu, Camp Road, Amravati, Dist-Amravati, State-Maharashtra, INDIA.
}

\begin{abstract}
In present study is to develop Gastro-Retentive controlled release in situ gel using natural and synthetic polymers. Gastro-retentive controlled release in situ gels were prepared to controlled drug delivery, to improve bioavailability, stability, reducing side effects. For the present work $3^{2}$ factorial designs was selected. The two independent variables were selected sodium alginate $\left(X_{1}\right)$ and ratio of polymers HPMC K4M: Gellum Gum $\left(\mathrm{X}_{2}\right)$ combined concentration of HPMC K4M and Gellum Gum was kept constant i.e. $2 \%$ and nine formulations were formulated as per experimental design, From evaluation of in situ gel formulation for factorial batches, formulation HPGG7 has show good gel strength, lag time $(98 \pm 0.57) \mathrm{sec}, \mathrm{pH}$ value $(7.4 \pm 0.20)$, drug contain (99.92 \pm $0.04) \%$, viscosity before and after gel (32715 \pm 1.15$)$ and (39850 \pm 1.73$) \mathrm{cp}$ respectively, total floating time more than 24 hours and also have good controlled release behaviour as it retard drug release up to $(79.2 \pm 0.50) \%$. Formulated in situ gel were stable at the selected temperature and humidity in storage for 3 month. Hence, from above it was concluded that formulation, in situ gel formulation HPPGG7 was containing sodium alginate $(1.5 \%) \mathrm{w} / \mathrm{v}$, HPMC K4M $(0.5 \%) \mathrm{w} / \mathrm{v}$, Gellum gum $(1.5 \%) \mathrm{w} / \mathrm{v}$, which could be most promising gastro-retentive in situ gel formulation. It was concluded that the prepared controlled release in situ gel of Diltiazem Hydrochloride may prove to be potential candidate for safe and effective controlled drug delivery for extended period of time.
\end{abstract}

Key world: Diltiazem HCL, Gastro-retentive In situ Gel, HPMC, Sodium Alginate, Tri-Sodium Citrate.

\section{INTRODUCTION}

Today the enhancement of bioavailability and development of continuous controlled release formulations has tremendous impact on the drug delivery field especially for drugs with a narrow absorption window. ${ }^{1}$ However, conventional oral liquid dosage forms are limited by insufficient retention in the upper gastric region, thus lead to bioavailability complications. From this the requisites to prolong the residence time of such dosage forms in the stomach leads to an important approach including decrease in the density to stimulate floating in the gastric fluids and thus gastro-retentive sustained release dosage form is reached. ${ }^{2}$ This new revolution that has been achieved in sustained drug delivery system represents today by floating in situ gel system. In this system, a solution of low viscosity can be easily applied; which upon reaching gastric contents it undergoes polymeric changes; thus producing a viscous in situ gel of density lower than the gastric fluids. ${ }^{3}$

Dosage forms for gastro-retentive drug delivery systems include floating; swelling; inflation; adhesion; high-density
Submission Date : 22-01-2016 Revision Date : 29-02-2016 Accepted Date : :06-04-2016

DOI: 10.5530/ijper.50.3.36 Correspondence: Nishan Naresh Bobade Asst. Prof of Pharmaceutics, Vidyabharati College of Pharmacy, C. K. Naidu, Camp Road, Amravati, DistAmravati, State-Maharashtra, INDIA.

Mobile No: 9970912707 E-mail.: nishan01_vicky@ yahoo.co.in

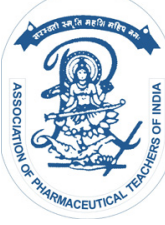

www.ijper.org 
systems and low density systems that increase the gastric residence time..$^{4-6}$ Gastric retention is useful for those drugs which (i) Act Locally; (ii) Have a narrow absorption window in the small intestinal region; (iii) Unstable in the intestinal environment; and (iv) Low solubility at high $\mathrm{pH}$ environment. ${ }^{7}$ Various dosage forms have been developed for gastric retention; these include, floating Tablets, ${ }^{8}$ floating beads, ${ }^{10}$ pellets, ${ }^{11}$ floating granules, ${ }^{12}$ and floating microspheres. ${ }^{12}$

In situ gel forming drug delivery is a type of muco-adhesive drug delivery system. In situ gel forming drug delivery system are a revolution in oral drug delivery. These hydrogels are liquid at room temperature but undergo gelation when in contact with body fluids or change in $\mathrm{pH}$. These in situ gels have a characteristic property of temperature dependant and cation induced gelation. ${ }^{13}$ these in situ gel preparations can be easily formulated in bulk, it gives site specific drug delivery and sustained action when compared to other conventional suspensions. The polymers which are used to prepare in situ gels can be termed as smart polymers. They are having the ability to change their physicochemical properties in response to the altered environmental conditions. ${ }^{14}$ The in situ gel formation occurs due to one or combination of different stimuli like $\mathrm{pH}$ change, temperature change, ionic activation etc. ${ }^{15}$

Diltiazem Hydrochloride, a calcium channel blocker, is widely used for the treatment of angina pectoris, hypertension and arrhythmias. ${ }^{16,17}$ It is administered orally in formulation such as (Tablets, Capsules, and Sustained Release Tablets/Capsules) and also parenterally (Intravenous). The usual dose of diltiazem Hydrochloride for antihypertension is $180-240 \mathrm{Mg} /$ day. ${ }^{14,16,18}$ The conventional Tablet and capsule is administered 3 or 4 times a day due to its short biological half-life of about 6 hours. The problems of frequent administration and variable low bioavailability (40-60\%) after oral administration of conventional Tablet or capsules have been attenuated by modifying diltiazem in the form of sustained or controlled release Tablet or capsules. ${ }^{16,19,14}$ The sustained or controlled release forms are administered two times a day due to its limited residence time in the gastrointestinal tract. ${ }^{16,20}$

The present research work was aimed to prepare controlled release gastro-retentive In situ gel for Diltiazem HCL to improve pharmacokinetic performance by using combination of Hydroxy Propyl Methyl Cellulose, Gellum Gum. The prepared formulation, In situ gel will become gel in contact with gastric $\mathrm{pH}$ and release drug in controlled manner up to 24 hours.

\section{MATERIAL}

Diltiazem Hydrochloride was obtained as gift sample from Pellet Pharma Ltd. Hyderabad. HPMC K4M was obtained as gift sample from colourcon Goa. Sodium alginate, gellum gum were procured from S.D. Fine chemicals, Mumbai, India. All other reagents used were of analytical grade commercially available from Merck Pvt. Ltd., Mumbai, India.

\section{METHOD}

\section{Selection of Active Pharmaceuticals Agents}

Diltiazem Hydrochloride, a calcium channel blocker, is widely used for the treatment of angina pectoris, hypertension and arrhythmias. ${ }^{16,17}$ The conventional Tablet and capsule is administered 3 or 4 times a day due to its short biological half-life of about 6 hours. The problems of frequent administration and variable low bioavailability (40-60\%) after oral administration of conventional dosage form. ${ }^{16,19,14}$

\section{Factorial Batch}

A factorial designs is used to evaluate two or more factor simultaneously. The treatments are combination of level of factors. The advantages of factorial designs over one factor at a time experiments include theirs efficiency and deletion of interaction. Intervention studies with two or more categorical explanatory variable leading to numerical outcome variable are called factorial designs. A factor is simply a categorical variable with two or more value refers as levels. A study in which there are two factors with theirs three levels called $3^{2}$ factorial designs. For the present work $3^{2}$ factorial was selected. The two independent variables were selected Sodium Alginate $\left(\mathrm{X}_{1}\right)$ and ratio of HPMC K4M: Gellum Gum $\left(\mathrm{X}_{2}\right)$ combined concentration of HPMC K4M and Gellum Gum was kept constant i.e 2\% and nine formulations were formulated as per experimental design. Amount variable in $3^{2}$ factorial designs batch and experimental design was shown in Table 1 and Table 2 respectively.

\section{Preparation of In situ Gel ${ }^{21-24}$}

Sodium alginate solutions of concentrations $(0.5 \%$, $1 \% 1.5 \%) \mathrm{w} / \mathrm{v}$ were prepared in deionised water containing $0.3 \% \mathrm{w} / \mathrm{v}$ of Tri Sodium citrate and $1.8 \% \mathrm{w} / \mathrm{v}$ of sodium methyl paraben. Sodium alginate solutions were heated to $70^{\circ} \mathrm{C}$ with stirring. After cooling to below $40^{\circ} \mathrm{C}$, gellum Gum, HPMC K4M was added with different concentration as per following formulation Table 3 . After homogeneous dispersion calculated amount of 
dose the drug and $1 \% \mathrm{w} / \mathrm{v}$ of calcium carbonate was added and dispersed well with continuous stirring.

\section{Evaluation of Controlled Release Gastro-Retentive In situ Gel}

\section{Drug and Polymer Compatibility Studies ${ }^{25,26}$}

\section{a) FTIR Spectroscopy}

The FTIR spectrum of drug was recorded on an infrared spectrophotometer (Shimadzu Affinity-1). IR spectrum of drug, polymers, and physical mixture of drug and polymer were recorded in the frequency range 400-4000 $\mathrm{cm}^{-1}$. The recorded significant peaks were noted and were matched with standard FTIR of drug. The FTIR spectrum was shown in Figure 1.

\section{b) Differential Scanning Calorimeter Analysis}

Thermal analysis was performed using system with differential scanning calorimeter equipped with a computerized data station. All samples were weighed and heated at a scanning rate of $10^{\circ} \mathrm{C} / \mathrm{min}$ between 30 and $300^{\circ} \mathrm{C}$ and $40 \mathrm{ml} / \mathrm{min}$ of nitrogen flow. The differential scanning calorimetry analysis gives an idea about the interaction of various materials at different temperature. It also allows us to study the possible degradation pathway of the materials. The DSC spectrum was shown in Figure 2.

\section{Standard Calibration Curve of Diltiazem $\mathrm{HCl}$ in $0.1 \mathrm{~N} \mathrm{HCL}^{25,26}$}

From solution having concentration $100 \mu \mathrm{g} / \mathrm{ml}$ aliquots of $0.2,0.4,0.6,0.8,1.0,1.2,1.4,1.6,1.8$, and $2 \mathrm{ml}$ were pipette out into $10 \mathrm{ml}$ volumetric flasks. The volume was made up to the mark with $0.1 \mathrm{~N}$ HCL to get the final concentration of $2,4,6,8,10,12,14,16,18$, and $20 \mu \mathrm{g} / \mathrm{ml}$ respectively. The absorbance of each concentration was measured at $236 \mathrm{~nm}$. A graph of absorbance versus concentration was plotted and it is shown in Figure 3. It shows straight line meaning the calibration curve obeys Beers law.

\section{pH Measurement ${ }^{21,27}$}

The $\mathrm{pH}$ was measured in each of the solution of sodium alginate based in situ solutions, using a calibrated digital $\mathrm{pH}$ meter at $27^{\circ} \mathrm{C}$. The measurements of $\mathrm{pH}$ of each data were in triplicate and the average values are given in Table 4.

\section{In vitro Floating Study ${ }^{28}$}

The in vitro floating study was carried out using USP dissolution apparatus II having $500 \mathrm{ml}$ of $0.1 \mathrm{~N} \mathrm{HCl}$ (pH 1.2) .The medium temperature was kept at $37^{\circ} \mathrm{C}$. Accurately weighed $10 \mathrm{~mL}$ of the prepared in situ gel formulations were drawn up using disposable syringe and placed into the Petridis (4.5 $\mathrm{mm}$ internal diameter) and finally the Petridis containing the formulation was kept in the dissolution vessel containing medium without much disturbance.

The time the formulation took to emerge on to the medium surface (Floating Lag Time) and the time over which the formulation constantly floated on the dissolution medium surface Duration of Floating) were noted. The measurements of floating lag time and total floating time of each data were in triplicate and the average values are given in Table 4.

\section{Characteristics of In situ Gel/ Gel Strength In-vitro Gelling Capacity ${ }^{29}$}

To evaluate the formulations for their in-vitro gelling capacity by visual method, colored solutions of in situ gel forming drug delivery system were prepared. The in-vitro gelling capacity of prepared formulations was measured by placing five $\mathrm{ml}$ of the gelation solution $(0.1 \mathrm{~N} \mathrm{HCl}, \mathrm{pH} 1.2)$ in a $15 \mathrm{ml}$ borosilicate glass test tube and maintained at $37 \pm 1{ }^{\circ} \mathrm{C}$ temperature. One $\mathrm{ml}$ of colored formulation solution was added with the help of pipette. The formulation was transferred in such a way that places the pipette at surface of fluid in test tube and formulation was slowly released from the pipette. As the solution comes in contact with gelation solution, it was immediately converted into stiff gel like structure. The gelling capacity of solution was evaluated on the basis of stiffness of formed gel and time period for which they formed gel remains as such. Color was added to give visualized appearance to formed gel. The in-vitro gelling capacity was graded in three categories on the basis of gelation time and time period for which they formed gel remains.

$(+)$ Gels after few minutes, dispersed rapidly

$(++)$ Gelation immediate remains for few hours

$(+++)$ Gelation immediate remains for an extended period.

\section{Determination of drug content $(\%)^{30}$}

A known quantity $5 \mathrm{ml}$ of the prepared solutions was stirred with $100 \mathrm{ml}$ of $0.1 \mathrm{~N} \mathrm{HCl}$ for 2 hrs. The sample was then centrifuged at $2000 \mathrm{rpm}$ and the filtrate was measured by using UV spectrophotometer at $236 \mathrm{~nm}$. The measurements of drug content of each data were recorded in triplicate and the average values are given in Table 4.

\section{Viscosity Measurement of the In-situ Gelling Solutions ${ }^{31,32}$}

Viscosity before gel (Sol) were determined using a brookfield digital viscometer (Model no LVDV 2P230) 
with the spindle number 5. The temperature of the $25 \mathrm{~mL}$ samples was kept at $25 \pm 1{ }^{\circ} \mathrm{C}$ during each measurement which lasted $60 \mathrm{sec}$, and the experiments were performed in triplicate. The average values are given in Table 4.

Viscosity after gel (gel) were determined using a Brookfield digital viscometer (Model no LVDV 2P230) with the spindle number $6.10 \mathrm{ml}$ of $0.1 \mathrm{~N} \mathrm{HCL}$ was added to $25 \mathrm{ml}$ of in situ gel for gelation after 2 min sample was analysed. The temperature of samples was kept at $25 \pm 1{ }^{\circ} \mathrm{C}$ during each measurement which lasted $60 \mathrm{sec}$, and the experiments were performed in triplicate. The average values are given in Table 4.

\section{In vitro Drug Release Studies $28,31,33$}

Cumulative drug releases of the in-situ gelling preparations were carried out with some modification using USP 2 dissolution test apparatus with paddle stirrer at a rate of $50 \mathrm{rpm}$. The slow speed prevented breaking of the gelled formulation and ensured a low level of agitation. The dissolution medium used was $900 \mathrm{~mL}$ of a $0.1 \mathrm{~N}$ solution of HCL ( $\mathrm{pH} 1.2$ ), and the temperature was kept at $37^{\circ} \mathrm{C} \pm 2^{\circ} \mathrm{C}$. A $10 \mathrm{~mL}$ sample was withdrawn using a disposable syringe; the needle was then wiped clean and the excess sample removed from the needle end. The sample was then gently transferred into a Petridis which was then immersed into the dissolution medium without much turbulence. At hourly intervals, an accurately measured $10 \mathrm{~mL}$ sample of the dissolution medium was removed with the help of a hypodermic syringe, diluted to $50 \mathrm{~mL}$ with $0.1 \mathrm{~N} \mathrm{HCL}$ and absorbance of the sample was read at $236 \mathrm{~nm}$ using a UV spectrophotometer for analysis of drug. Each time, the sample withdrawn was replenished with the same amount of the pre-warmed 0.1N HCL. Each experiment was continued for a period of 24 hours in triplicate. The experiments were performed in triplicate. The cumulative drug release of factorial batches is shown in Table 5 and Figure 4.

\section{Rheological Studies 21,28}

A rheology study for In situ gel for gastro-retentive system by using brookfield viscometer was studied. $25 \mathrm{ml}$ of in situ gel formulations were placed in nescller cylinder which properly cut for required quaintly. The viscosity measurements were done at rpm of 10, 20, 30, 40, 50 60 and up to 100 for $60 \mathrm{sec}$ agitation at temperature of $37^{\circ} \mathrm{C} \pm 2^{\circ} \mathrm{C}$ and similarly viscosity measurement were done reverse order. Experiments were performed in triplicate. Rheograms were constructed by plotting the dial readings on the $\mathrm{x}$-axis and $\mathrm{rpm}$ values along the $y$-axis. The rheological behavior of factorial batches is shown in Figure 5.

\section{Kinetics of Drug Release ${ }^{34}$}

Dissolution profile of all the formulations were fitted to zero order kinetics, first order kinetics, Higuchi, Hixson-Crowell, Korsmeyer and Pepas to ascertain the kinetics modelling of dug release by using a PSP Disso version 2.08 and the model with higher correlation was consider to be the best model observation were submersed in Table 6 .

In order to know drug release mechanism the data was further analysed by korsmeyer pepas equation and value if $\mathrm{n}$ i.e. release exponent was calculated. The $\mathrm{n}$ value is used to interpret the release mechanism as is shown in Table 6.

\section{Stability Studies ${ }^{35-37}$}

In the present study, stability studies were carried out at $\left.40^{\circ} \mathrm{C} \pm 2^{\circ}, 75 \pm 5 \% \mathrm{RH}\right),\left(25^{\circ} \mathrm{C} \pm 2^{\circ} \mathrm{C}, 75 \% \pm 5 \% \mathrm{RH}\right)$ and $\left(40^{\circ} \mathrm{C} \pm 2^{\circ} \mathrm{C}, 75 \% \pm 5 \% \mathrm{RH}\right)$ for a specific time period up to 3 month for the optimized formulation. The optimized formulation was analyzed for the drug contents study, $\mathrm{pH}$, lag time (sec), floating time (hours), viscosity before gel (cp), viscosity after gel (cp), cumulative drug release (\%). Experiments were performed in triplicate and average values are noted. The Stability Studies data was shown in Table 7.

\section{RESULTS AND DISCUSSION}

Diltiazem Hydrochloride, a calcium channel blocker, is widely used for the treatment of angina pectoris, hypertension and arrhythmias. The conventional Tablet and capsule is administered 3 or 4 times a day due to its short biological half-life of about 6 hours. The problems of frequent administration and variable low bioavailability (40-60\%) after oral administration of conventional dosage form.

In situ gel forming drug delivery systems are a revolution in oral drug delivery. These hydrogels are liquids at room temperature but undergo gelation when in contact with body fluids or change in $\mathrm{pH}$. These have a characteristic property of temperature dependant and cation induced gelation. This gelation involves formation of the double helical junction zones followed by aggregation of the double helical segments to form a three dimensional network by complexation with cations and hydrogen bonding. In present works, sodium alginate, HPMC K4M, gellum gum were used for development of controlled release formulations with various concentrations of the polymers.

Alginic acid is a linear block polysaccharide copolymer made of $\beta$-D-mannuronic acid $(\mathrm{M})$ and $\alpha$-L-guluronic acid $(\mathrm{G})$ residues joined by 1,4 glycosidic linkages. The 


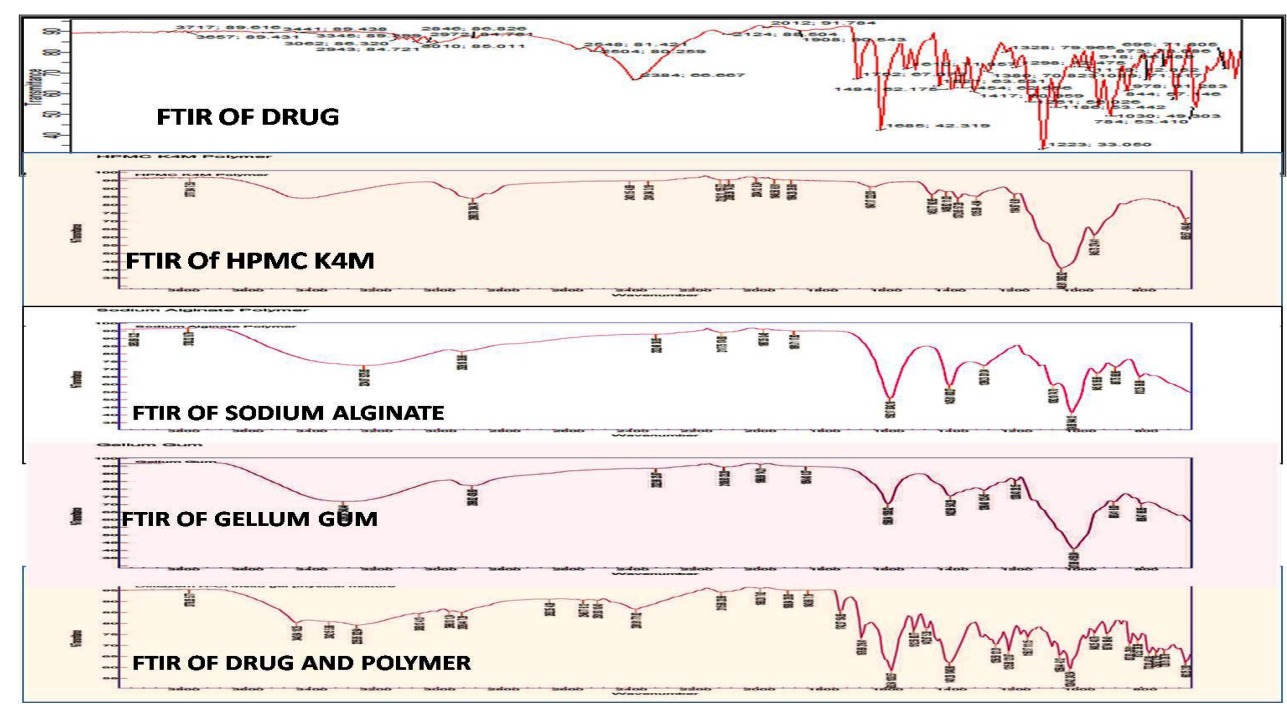

Figure 1: FTIR Spectra of Drug, Polymer and Physical Mixture.
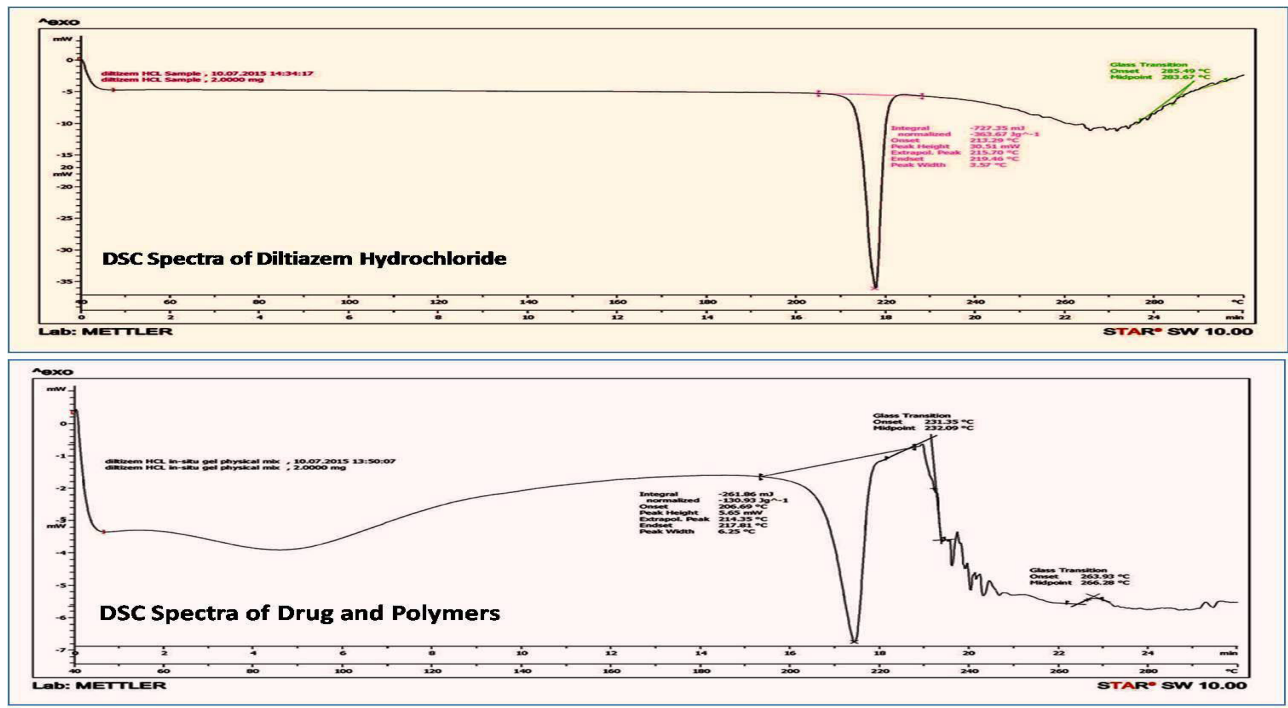

Figure 2: DSC Spectra of Drug and Physical Mixture.

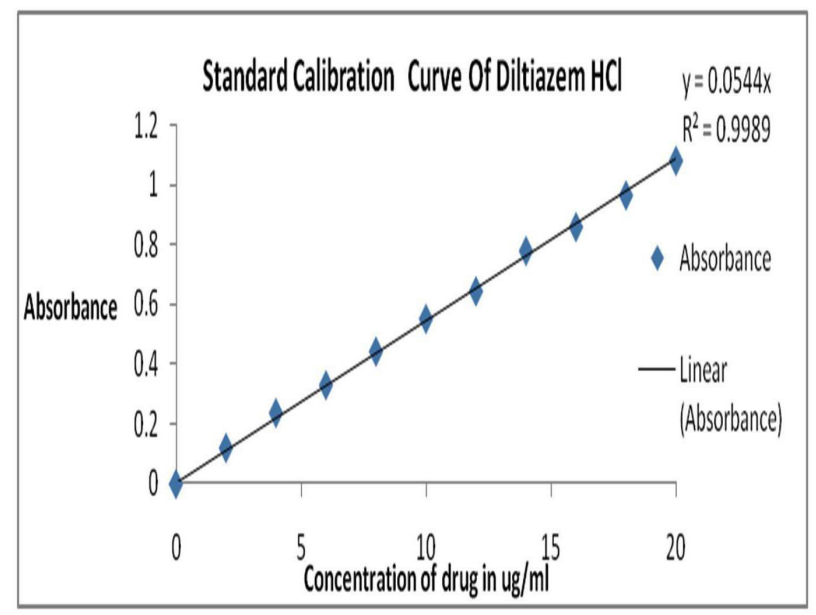

Figure 3: Standard Calibration Curve of Diltiazem HCL in $0.1 \mathrm{~N}$ HCL.

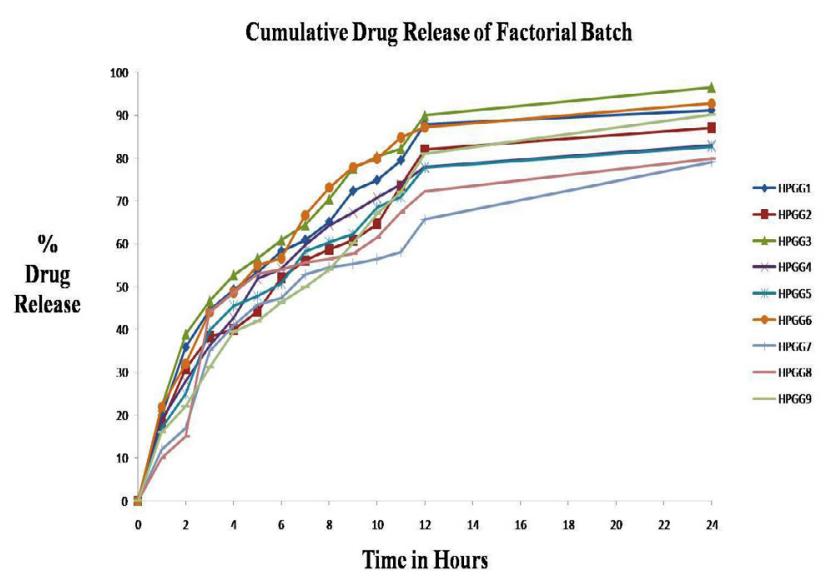

Figure 4: Cumulative Drug Release of Factorial Batch. 


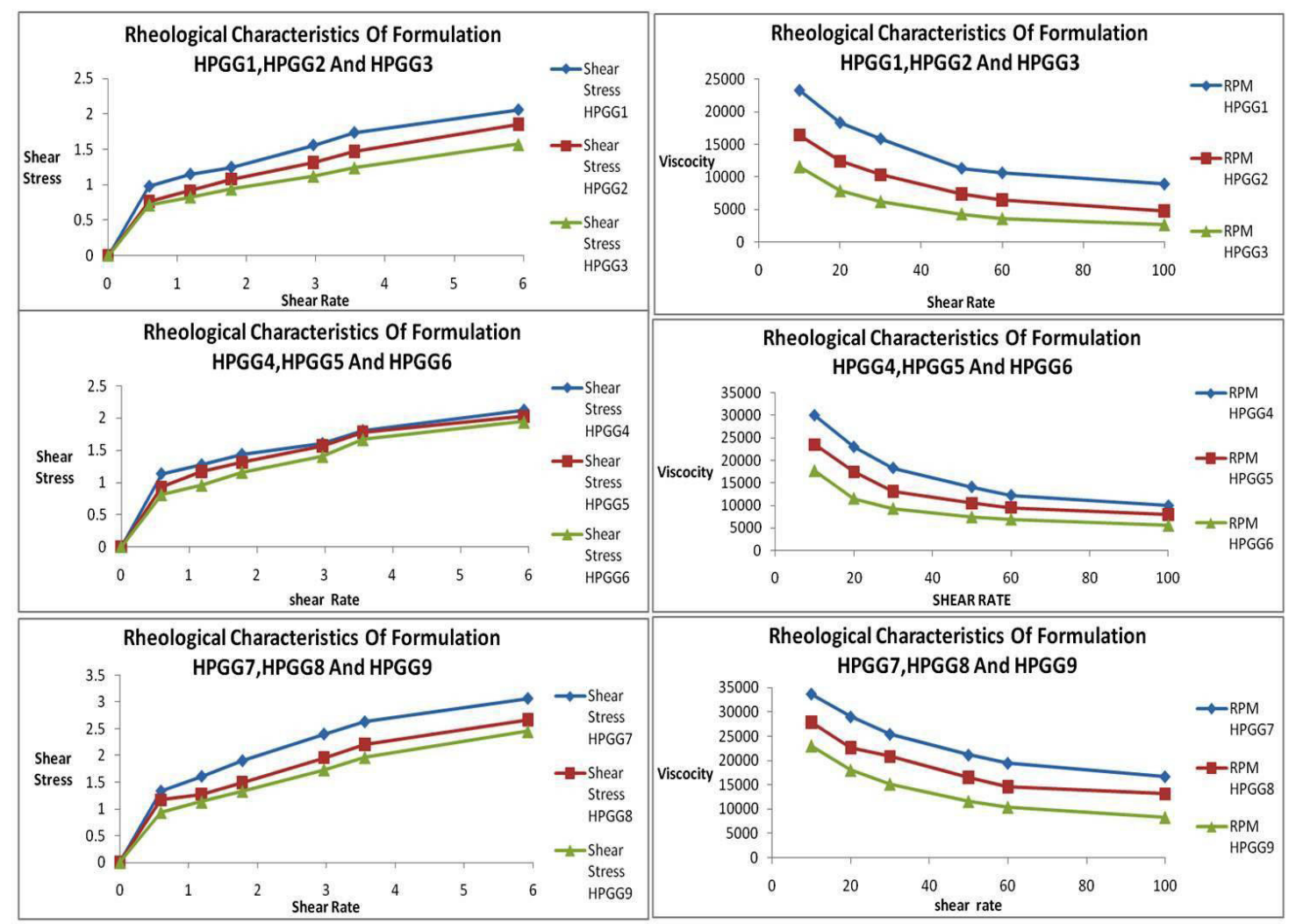

Figure 5: Rheological Behavior of Factorial Batches.

Table 1: Amount of Variable in 32 Factorial Designs Batches

\begin{tabular}{|c|c|c|}
\hline \multirow{2}{*}{ Coded Values } & X1 & \multicolumn{2}{|c|}{ Actual Values } \\
\cline { 2 - 3 } & X2 \\
\hline-1 & Sodium Alginate $0.5 \%$ & Ratio of HPMC : Gellum Gum (1:3) \\
\hline 0 & Sodium Alginate 1\% & Ratio of HPMC : Gellum Gum (2:2) \\
\hline+1 & Sodium Alginate 1.5\% & Ratio of HPMC : Gellum Gum (3:1) \\
\hline
\end{tabular}

Table 2: Experimental Designs

\begin{tabular}{|c|c|c|}
\hline \multirow{2}{*}{ Formulation Code } & \multicolumn{2}{|c|}{ Coded value } \\
\cline { 2 - 3 } & $\mathbf{X 1}$ & -1 \\
\hline HPGG1 & -1 & 0 \\
\hline HPGG2 & -1 & +1 \\
\hline HPGG3 & -1 & -1 \\
\hline HPGG4 & 0 & 0 \\
\hline HPGG5 & 0 & +1 \\
\hline HPGG6 & 0 & -1 \\
\hline HPGG7 & +1 & 0 \\
\hline
\end{tabular}




\begin{tabular}{|c|c|c|c|c|c|c|c|c|}
\hline \multirow[b]{2}{*}{ Code } & \multicolumn{8}{|c|}{ Name of Ingredients } \\
\hline & $\begin{array}{c}\text { Diltiazem } \\
\text { HCL } \\
(\%) w / v\end{array}$ & $\begin{array}{c}\text { Sodium } \\
\text { Alginate } \\
(\%) w / v\end{array}$ & $\begin{array}{c}\text { HPMC } \\
\text { K4M } \\
(\%) w / v\end{array}$ & $\begin{array}{l}\text { Gellum Gum } \\
(\%) w / v\end{array}$ & $\begin{array}{c}\text { Calcium } \\
\text { Carbonate } \\
(\%) w / v\end{array}$ & $\begin{array}{c}\text { Tri-sodium } \\
\text { Citrate } \\
(\%) w / v\end{array}$ & $\begin{array}{c}\text { Sodium } \\
\text { Methyl } \\
\text { Paraben } \\
(\%) w / v\end{array}$ & $\begin{array}{c}\text { Deionised } \\
\text { Water }\end{array}$ \\
\hline HPGG1 & 1.8 & 0.5 & 0.50 & 1.5 & 1 & 0.3 & 1.8 & qs to $100 \mathrm{ml}$ \\
\hline HPGG2 & 1.8 & 0.5 & 1 & 1 & 1 & 0.3 & 1.8 & qs to $100 \mathrm{ml}$ \\
\hline HPGG3 & 1.8 & 0.5 & 1.5 & 0.50 & 1 & 0.3 & 1.8 & qs to $100 \mathrm{ml}$ \\
\hline HPGG4 & 1.8 & 1 & 0.50 & 1.5 & 1 & 0.3 & 1.8 & qs to $100 \mathrm{ml}$ \\
\hline HPGG5 & 1.8 & 1 & 1 & 1 & 1 & 0.3 & 1.8 & qs to $100 \mathrm{ml}$ \\
\hline HPGG6 & 1.8 & 1 & 1.5 & 0.50 & 1 & 0.3 & 1.8 & qs to $100 \mathrm{ml}$ \\
\hline HPGG7 & 1.8 & 1.5 & 0.50 & 1.5 & 1 & 0.3 & 1.8 & qs to $100 \mathrm{ml}$ \\
\hline HPGG8 & 1.8 & 1.5 & 1 & 1 & 1 & 0.3 & 1.8 & qs to $100 \mathrm{ml}$ \\
\hline HPGG9 & 1.8 & 1.5 & 1.5 & 0.50 & 1 & 0.3 & 1.8 & qs to $100 \mathrm{~m}$ \\
\hline
\end{tabular}

\begin{tabular}{|c|c|c|c|c|c|c|}
\hline $\begin{array}{c}\text { Formulation } \\
\text { Code }\end{array}$ & pH & $\begin{array}{l}\text { Lag } \\
\text { Time } \\
\text { (Sec) }\end{array}$ & $\begin{array}{c}\text { Total } \\
\text { Floating } \\
\text { (Time) }\end{array}$ & $\begin{array}{c}\text { Drug } \\
\text { Content (\%) }\end{array}$ & $\begin{array}{l}\text { Viscosity } \\
\text { Before Gel } \\
\text { (cp) }\end{array}$ & $\begin{array}{c}\text { Viscosity } \\
\text { After Gel (cp) }\end{array}$ \\
\hline HPGG1 & $7.2 \pm 0.20$ & $80 \pm 1.15$ & $>24$ & $98.57 \pm 0.82$ & $23265 \pm 2.88$ & $23843 \pm 1.73$ \\
\hline HPGG2 & $7.2 \pm 0.20$ & $74 \pm 1.15$ & $>24$ & $98.23 \pm 1.02$ & $16430 \pm 2.30$ & $17693 \pm 2.88$ \\
\hline HPGG3 & $7.2 \pm 0.20$ & $72 \pm 1.15$ & $>24$ & $98.14 \pm 1.073$ & $9595 \pm 1.15$ & $11253 \pm 1.73$ \\
\hline HPGG4 & $7.3 \pm 0.20$ & $84 \pm 2.30$ & $>24$ & $98.94 \pm 0.611$ & $27315 \pm 2.88$ & $29535 \pm 2.30$ \\
\hline HPGG5 & $7.3 \pm 0.20$ & $77 \pm 1.15$ & $>24$ & $98.74 \pm 0.72$ & $21480 \pm 5.19$ & $25480 \pm 2.30$ \\
\hline HPGG6 & $7.3 \pm 0.20$ & $74 \pm 2.30$ & $>24$ & $98.48 \pm 0.87$ & $14645 \pm 2.30$ & $18320 \pm 4.61$ \\
\hline HPGG7 & $7.4 \pm 0.20$ & $98 \pm 0.57$ & $>24$ & $99.92 \pm 0.04$ & $32715 \pm 1.15$ & $39850 \pm 1.73$ \\
\hline HPGG8 & $7.4 \pm 0.20$ & $87 \pm 0.57$ & $>24$ & $99.49 \pm 0.29$ & $26880 \pm 5.19$ & $29530 \pm 5.19$ \\
\hline HPGG9 & $7.4 \pm 0.20$ & $82 \pm 3.46$ & $>24$ & $99.30 \pm 0.40$ & $22045 \pm 1.15$ & $29440 \pm 1.73$ \\
\hline
\end{tabular}

proportion and the arrangement of the blocks along the polymer chain much depend on the algal source. The aqueous alginate solutions could form firm gels in presence of di-and tri-valent metal ions by a cooperative process involving consecutive guluronic residues in the $G$ blocks of the alginate chain. This property has been widely used for preparation of vehicles for sustained delivery of the bioactive molecules. Alginates show characteristic ion binding for multivalent cations and this forms the basis for their gelling properties. The alginate binding leads to the formation of covalent bonds leading to the perception of the insoluble hydrogel. Cross-linking processes stiffen and roughen the polymer and reduce the swelling in solvents. This generally leads to a reduction in the permeability of different solutes hindering the release of embodied drugs in alginate matrices, allowing these systems to be used in controlling the drug release. Matrices containing sodium alginate and sodium-calcium alginate have been investigated for their sustained release effects. To achieve repeatability in gelation we used a source of $\mathrm{Ca}^{++}$ions in the solution itself. Due to the free calcium ions being complexes with sodium citrate, gelation was delayed until the administered solution reached the acidic environment of the stomach. Gelation was then occurred as the complex broke down and the $\mathrm{Ca}^{++}$ions were released. The calcium carbonate present in the gelling formulation released carbon dioxide in gastric environment thereby making the formulation porous and buoyant and prolonging the residence time. This floating in stomach provides the potential to sustain the drug release over a long period of time. Gelation of sodium alginate will occur in the presence of $\mathrm{H}^{+}$ions, the soft alginic acid gels that are formed are generally suitable as vehicles for drug delivery. In this study $\mathrm{Ca}^{++}$ions were included in the formulation for induc- 


\begin{tabular}{|c|c|c|c|c|c|c|c|c|c|c|c|c|c|}
\hline \multirow{9}{*}{ 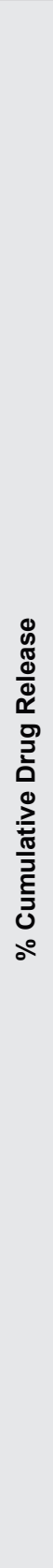 } & 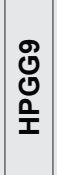 & $\begin{array}{l}8 \\
+1 \\
8\end{array}$ & $\begin{array}{l}\mathcal{N} \\
\mathcal{O} \\
+1 \\
0 \\
\underline{T}\end{array}$ & $\begin{array}{l}\infty \\
0 \\
0 \\
+1 \\
\mathbb{N}\end{array}$ & 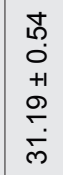 & 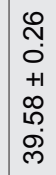 & 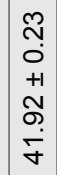 & $\begin{array}{l}f \\
f \\
0 \\
+1 \\
\mathbb{1} \\
\tilde{J} \\
\dot{\theta}\end{array}$ & 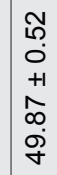 & $\begin{array}{l}\mathscr{8} \\
0 \\
0 \\
+1 \\
0 \\
\mathscr{O} \\
\tilde{B} \\
\text {. }\end{array}$ & $\begin{array}{l}\bar{N} \\
\mathfrak{n} \\
+1 \\
\tilde{N} \\
\dot{0}\end{array}$ & $\begin{array}{l}2 \\
0 \\
0 \\
+1 \\
\tilde{1} \\
\delta \\
\hat{1}\end{array}$ & 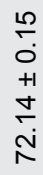 \\
\hline & $\begin{array}{l}\text { o } \\
\text { ญू } \\
\text { 모 }\end{array}$ & $\begin{array}{l}8 \\
+1 \\
8\end{array}$ & $\begin{array}{l}8 \\
0 \\
0 \\
+1 \\
0\end{array}$ & $\begin{array}{l}0 \\
0 \\
0 \\
+1 \\
10\end{array}$ & 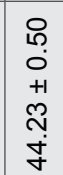 & 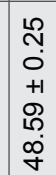 & 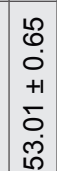 & 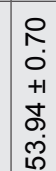 & 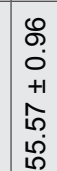 & $\begin{array}{l}\infty \\
\text { O } \\
0 \\
+1 \\
\mathscr{J} \\
\tilde{m} \\
i \\
i\end{array}$ & $\begin{array}{l}\overline{0} \\
\tilde{n} \\
+1 \\
\tilde{D} \\
\infty \\
\hat{n} \\
\end{array}$ & $\begin{array}{l}\tilde{N} \\
0 \\
+1 \\
+1 \\
\tilde{L} \\
\tilde{L} \\
\end{array}$ & 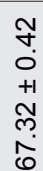 \\
\hline & 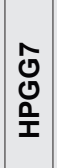 & $\begin{array}{l}8 \\
+1 \\
8\end{array}$ & $\begin{array}{l}\mathscr{8} \\
0 \\
0 \\
+1 \\
\mathbb{1}\end{array}$ & $\begin{array}{l}8 \\
0 \\
0 \\
+1 \\
-1\end{array}$ & $\begin{array}{l}\mathscr{8} \\
0 \\
0 \\
+1 \\
+ \\
\infty \\
0 \\
\dot{0}\end{array}$ & 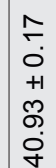 & 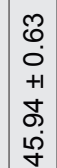 & 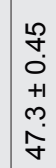 & $\begin{array}{l}\hat{L} \\
0 \\
+1 \\
0 \\
0 \\
\sim \\
\end{array}$ & $\begin{array}{l}5 \\
\tilde{m} \\
0 \\
+1 \\
10 \\
\dot{0} \\
0\end{array}$ & 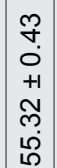 & $\begin{array}{l}\mathcal{N} \\
\tilde{N} \\
0 \\
+1 \\
\infty \\
0 \\
0 \\
0 \\
0\end{array}$ & $\begin{array}{l}8 \\
0 \\
0 \\
+1 \\
\infty \\
0 \\
\infty \\
0\end{array}$ \\
\hline & $\begin{array}{l}0 \\
0 \\
0 \\
\text { 모 } \\
\text { 이 }\end{array}$ & $\begin{array}{l}8 \\
+1 \\
8\end{array}$ & $\begin{array}{l}\infty \\
0 \\
0 \\
+1 \\
\mathbb{N}\end{array}$ & $\begin{array}{l}\infty \\
0 \\
0 \\
+1 \\
\sim \\
ల\end{array}$ & $\begin{array}{l}\hat{0} \\
0 \\
+1 \\
\tilde{J}\end{array}$ & 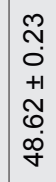 & $\begin{array}{l}0 \\
0 \\
0 \\
+1 \\
+1 \\
0 \\
0 \\
\dot{1}\end{array}$ & 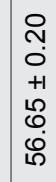 & $\begin{array}{l}\infty \\
\check{0} \\
+1 \\
+ \\
\& \\
\dot{\theta}\end{array}$ & 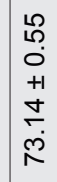 & $\begin{array}{c}\stackrel{̃}{N} \\
\vdots \\
+1 \\
+ \\
\tilde{N} \\
\hat{N}\end{array}$ & $\begin{array}{l}\hat{\varphi} \\
\dot{0} \\
+1 \\
\mathscr{O} \\
\dot{\rho} \\
\hat{\rho}\end{array}$ & 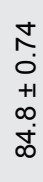 \\
\hline & $\begin{array}{l}\text { 号 } \\
\text { ग } \\
\text { 모 }\end{array}$ & $\begin{array}{l}8 \\
+1 \\
8\end{array}$ & 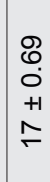 & $\begin{array}{l}\infty \\
0 \\
0 \\
+1 \\
\infty \\
N\end{array}$ & 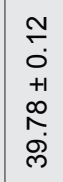 & 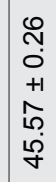 & $\begin{array}{l}\mathcal{M} \\
\tilde{0} \\
+1 \\
+ \\
\tilde{L} \\
\tilde{\sigma}\end{array}$ & $\begin{array}{l}0 \\
0 \\
0 \\
+1 \\
+1 \\
o \\
0 \\
0 \\
i n\end{array}$ & $\begin{array}{l}\tilde{n} \\
0 \\
+1 \\
+1 \\
\infty \\
\infty\end{array}$ & $\begin{array}{l}\infty \\
\tilde{m} \\
0 \\
+1 \\
+ \\
\tilde{\sigma} \\
0 \\
0\end{array}$ & $\begin{array}{c}\hat{f} \\
0 \\
+1 \\
0 \\
\tilde{D} \\
\tilde{U}\end{array}$ & $\begin{array}{l}\infty \\
0 \\
0 \\
+1 \\
0 \\
0 \\
0 \\
0 \\
0\end{array}$ & 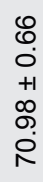 \\
\hline & $\begin{array}{l}\text { J } \\
\text { ญू } \\
\text { 묻 }\end{array}$ & $\begin{array}{l}8 \\
+1 \\
8\end{array}$ & $\begin{array}{l}\tilde{\sigma} \\
\dot{0} \\
+1 \\
\stackrel{+}{\circ}\end{array}$ & $\begin{array}{l}\mathcal{N} \\
0 \\
0 \\
+1 \\
o \\
N\end{array}$ & $\begin{array}{l}\infty \\
\tilde{O} \\
+1 \\
\tilde{N} \\
\dot{D} \\
\tilde{N}\end{array}$ & 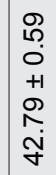 & \begin{tabular}{l}
$\mathscr{8}$ \\
0 \\
0 \\
+1 \\
$\infty$ \\
$\delta$ \\
\hdashline \\
$i$
\end{tabular} & 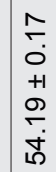 & $\begin{array}{l}\hat{L} \\
0 \\
0 \\
+1 \\
N \\
N \\
0 \\
\delta\end{array}$ & $\begin{array}{l}\text { o } \\
0 \\
0 \\
+1 \\
0 \\
0 \\
\tilde{0}\end{array}$ & $\begin{array}{l}\hat{N} \\
0 \\
+1 \\
\tilde{N} \\
\tilde{N} \\
\hat{0}\end{array}$ & $\begin{array}{l}L \\
0 \\
0 \\
0 \\
+1 \\
L \\
\infty \\
0 \\
0\end{array}$ & 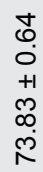 \\
\hline & $\begin{array}{l}0 \\
0 \\
0 \\
\text { 모 }\end{array}$ & $\begin{array}{l}8 \\
+1 \\
8\end{array}$ & $\begin{array}{l}\bar{\delta} \\
\dot{0} \\
+1 \\
\tilde{N}\end{array}$ & $\begin{array}{l}\infty \\
0 \\
0 \\
+1 \\
\infty \\
\infty \\
\infty \\
\infty\end{array}$ & $\begin{array}{l}\Gamma \\
i \\
0 \\
+1 \\
0 \\
0 \\
0 \\
0\end{array}$ & $\begin{array}{l}\infty \\
i \\
0 \\
0 \\
+1 \\
N \\
\hat{N} \\
\tilde{N}\end{array}$ & $\begin{array}{l}0 \\
0 \\
0 \\
+1 \\
0 \\
0 \\
0 \\
0\end{array}$ & 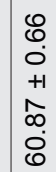 & $\begin{array}{l}\tilde{m} \\
0 \\
+1 \\
\infty \\
0 \\
\tilde{j}\end{array}$ & 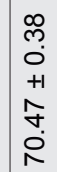 & 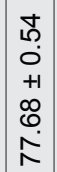 & 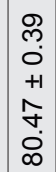 & $\begin{array}{l}\stackrel{2}{N} \\
\text {. } \\
+1 \\
\text { N } \\
\text { N }\end{array}$ \\
\hline & 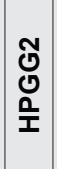 & $\begin{array}{l}8 \\
+1 \\
8\end{array}$ & $\begin{array}{l}\sigma \\
\delta \\
0 \\
+1 \\
+1 \\
\infty \\
\check{r}\end{array}$ & $\begin{array}{l}8 \\
\varnothing \\
0 \\
+1 \\
\delta \\
\delta \\
\dot{m}\end{array}$ & $\begin{array}{l}\tilde{N} \\
0 \\
+1 \\
\sim \\
\infty \\
\infty \\
\infty\end{array}$ & $\begin{array}{l}\tilde{J} \\
\dot{O} \\
\dot{+} \\
+1 \\
\tilde{O} \\
\tilde{O} \\
\dot{O}\end{array}$ & \begin{tabular}{l}
0 \\
\hdashline \\
0 \\
+1 \\
$\sigma$ \\
$\sigma$ \\
$\dot{J}$
\end{tabular} & 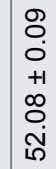 & $\begin{array}{l}8 \\
0 \\
0 \\
+1 \\
1 \\
0 \\
0 \\
0\end{array}$ & $\begin{array}{l}0 \\
\infty \\
0 \\
0 \\
+1 \\
\rho \\
\rho \\
\infty \\
\infty\end{array}$ & $\begin{array}{l}0 \\
0 \\
0 \\
+1 \\
+1 \\
0 \\
0 \\
0 \\
0\end{array}$ & $\begin{array}{l}\tilde{0} \\
0 \\
0 \\
+1 \\
\infty \\
0 \\
0 \\
0\end{array}$ & 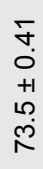 \\
\hline & $\begin{array}{l}\bar{ঠ} \\
\text { ㅁ } \\
\frac{1}{1}\end{array}$ & $\begin{array}{l}8 \\
+1 \\
8\end{array}$ & $\begin{array}{l}\tilde{0} \\
0 \\
0 \\
+1 \\
\stackrel{N}{N}\end{array}$ & $\begin{array}{c}\infty \\
m \\
0 \\
+1 \\
\sim \\
\infty \\
\infty \\
\infty\end{array}$ & 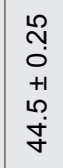 & $\begin{array}{l}\tilde{N} \\
0 \\
+1 \\
+1 \\
\tilde{\sigma} \\
\dot{\sigma}\end{array}$ & $\begin{array}{l}\mathscr{N} \\
\tilde{D} \\
+1 \\
+1 \\
\tilde{N} \\
\tilde{D} \\
\tilde{D}\end{array}$ & $\begin{array}{l}8 \\
0 \\
0 \\
+1 \\
\tilde{1} \\
0 \\
0 \\
0\end{array}$ & $\begin{array}{l}\mathcal{N} \\
\check{0} \\
+1 \\
\sim \\
\tilde{O} \\
\delta \\
0\end{array}$ & $\begin{array}{l}\tilde{n} \\
0 \\
+1 \\
\check{1} \\
\dot{0}\end{array}$ & $\begin{array}{l}0 \\
0 \\
0 \\
+1 \\
0 \\
0 \\
\mathbb{N} \\
\stackrel{N}{1}\end{array}$ & 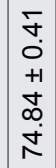 & $\begin{array}{l}8 \\
0 \\
0 \\
+1 \\
0 \\
0 \\
0\end{array}$ \\
\hline & & 0 & - & $N$ & $m$ & $\nabla$ & in & 0 & N & $\infty$ & o & 우 & $F$ \\
\hline
\end{tabular}

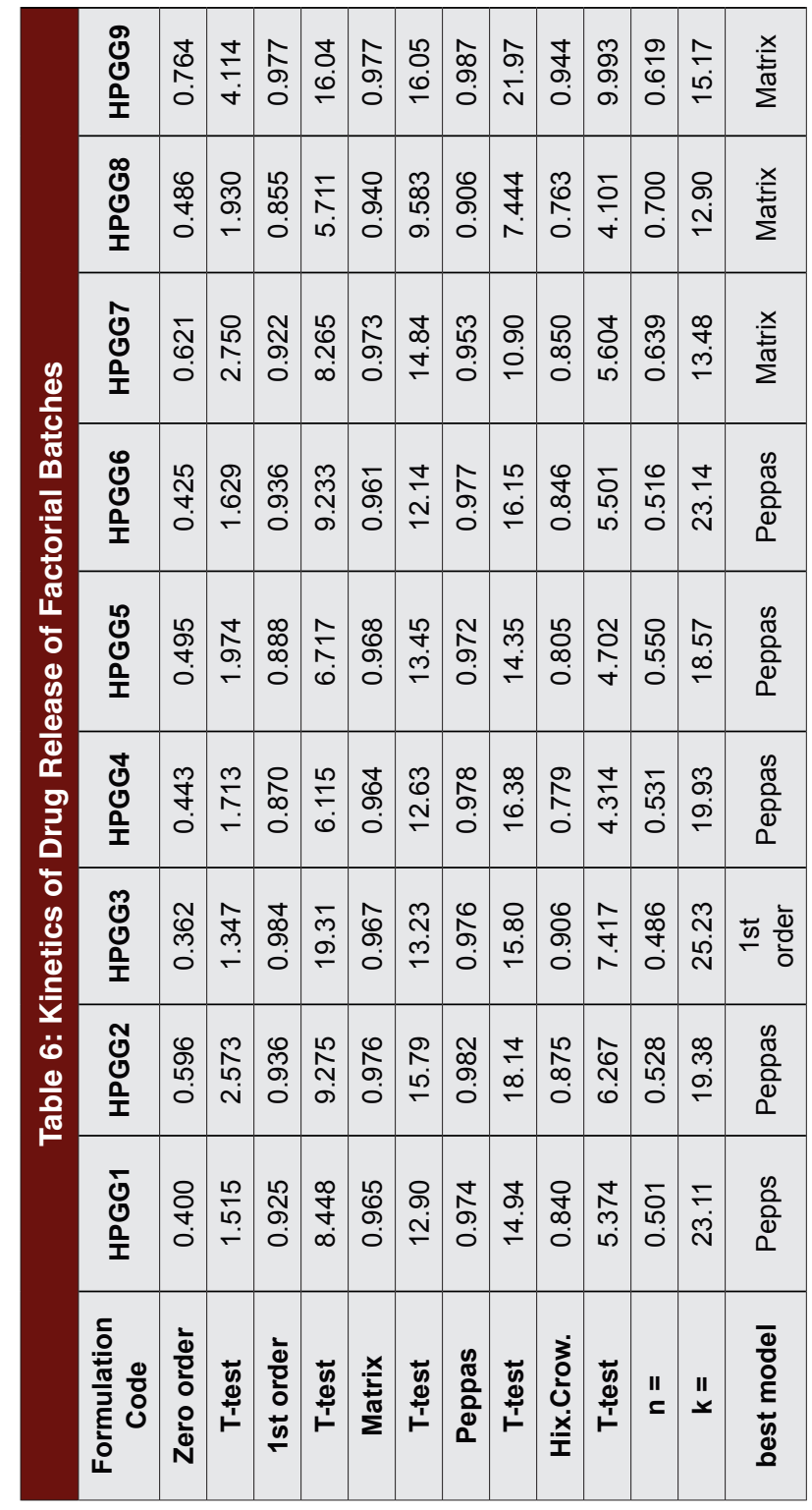




\begin{tabular}{|c|c|c|c|c|}
\hline \multicolumn{5}{|c|}{$10^{\circ} \mathrm{C} \pm 2{ }^{\circ} \mathrm{C}, 75 \% \pm 5 \% \mathrm{RH}$} \\
\hline Evaluation Parameter & 0 Month & 2 Month & 3 Month & 6 Month \\
\hline Drug Content (\%) & $99.92 \pm 0.04$ & $99.62 \pm 0.58$ & $99.52 \pm 0.35$ & $99.11 \pm 0.25$ \\
\hline $\mathrm{pH}$ & $7.4 \pm 0.20$ & $7.4 \pm 0.20$ & $7.4 \pm 0.20$ & $7.4 \pm 0.20$ \\
\hline Lag Time(Sec) & $98 \pm 0.57$ & $98 \pm 0.11$ & $98 \pm 0.65$ & $98 \pm 0.85$ \\
\hline Floating Time (Hours) & 24 & 24 & 24 & 24 \\
\hline Viscosity Before Gel (cp) & $32715 \pm 1.15$ & $32711 \pm 1.45$ & $32719 \pm 1.89$ & $32721 \pm 1.87$ \\
\hline Viscosity After Gel (cp) & $39850 \pm 0.73$ & $39852 \pm 0.73$ & $39853 \pm 0.73$ & $398553 \pm 0.73$ \\
\hline $\begin{array}{l}\text { Cumulative Drug } \\
\text { Release (\%) }\end{array}$ & $79.2 \pm 0.50$ & $79.45 \pm 0.22$ & $79.82 \pm 0.55$ & $79.52 \pm 0.57$ \\
\hline \multicolumn{5}{|c|}{$25^{\circ} \mathrm{C} \pm 2{ }^{\circ} \mathrm{C}, 75 \% \pm 5 \% \mathrm{RH}$} \\
\hline Evaluation Parameter & 0 Month & 2 Month & 3 Month & 6 Month \\
\hline Drug Content (\%) & $99.92 \pm 0.04$ & $99.62 \pm 0.78$ & $99.55 \pm 0.12$ & $99.53 \pm 0.56$ \\
\hline $\mathrm{pH}$ & $7.4 \pm 0.20$ & $7.4 \pm 0.22$ & $7.4 \pm 0.01$ & $7.4 \pm 0.01$ \\
\hline Lag Time(Sec) & $98 \pm 0.57$ & $98 \pm 0.65$ & $98 \pm 0.75$ & $98 \pm 0.82$ \\
\hline Floating Time (Hours) & 24 & 24 & 24 & 24 \\
\hline Viscosity Before Gel (cp) & $32715 \pm 1.15$ & $32715 \pm 1.23$ & $32715 \pm 1.10$ & $32715 \pm 1.25$ \\
\hline Viscosity After Gel (cp) & $39850 \pm 0.73$ & $39852 \pm 0.15$ & $39850 \pm 0.87$ & $39859 \pm 0.02$ \\
\hline $\begin{array}{l}\text { Cumulative Drug } \\
\text { Release }(\%)\end{array}$ & $79.2 \pm 0.50$ & $79.26 \pm 0.50$ & $79.24 \pm 0.50$ & $79.29 \pm 0.50$ \\
\hline \multicolumn{5}{|c|}{$40{ }^{\circ} \mathrm{C} \pm 2{ }^{\circ} \mathrm{C}, 75 \% \pm 5 \% \mathrm{RH}$} \\
\hline Evaluation Parameter & 0 Month & 2 Month & 3 Month & 6 Month \\
\hline Drug Content (\%) & $99.92 \pm 0.04$ & $99.92 \pm 0.57$ & $99.92 \pm 0.22$ & $99.92 \pm 0.22$ \\
\hline $\mathrm{pH}$ & $7.4 \pm 0.20$ & $7.4 \pm 0.28$ & $7.4 \pm 0.23$ & $7.4 \pm 0.24$ \\
\hline Lag Time(Sec) & $98 \pm 0.57$ & $98 \pm 0.59$ & $98 \pm 0.65$ & $98 \pm 0.87$ \\
\hline Floating Time (Hours) & 24 & 24 & 24 & 24 \\
\hline Viscocity Before Gel (cp) & $32715 \pm 1.45$ & $32715 \pm 1.32$ & $32715 \pm 1.02$ & $32715 \pm 1.89$ \\
\hline Viscocity After Gel (cp) & $39850 \pm 0.73$ & $39852 \pm 0.73$ & $39859 \pm 0.73$ & $39850 \pm 0.73$ \\
\hline $\begin{array}{l}\text { Cumulative Drug } \\
\text { Release }(\%)\end{array}$ & $79.2 \pm 0.50$ & $79.45 \pm 0.43$ & $79.89 \pm 0.12$ & $79.78 \pm 0.12$ \\
\hline
\end{tabular}

tion of alginate gelation. However, for ease of administration we required the formulation to be in the fluid (sol) state. This was achieved by addition of sufficient sodium citrate to the formulation to form a complex with all of the $\mathrm{Ca}^{++}$ions present in the formulation and hence to effectively remove them from solution. In the acidic environment of the stomach the complex is broken down and the $\mathrm{Ca}^{++}$ions released cause gelation to occur. HPMC K4M was selected for formulations to maintain viscosity and releases behaviour from the formulations. The viscosity is an important variable because it effects the gelation of the solutions, flow of the formulation and time required for the gelation. The viscosity is dependent on the concentration of the polymers. Methyl-paraben is widely used as an antimicrobial preservative in cosmetics, food products, and pharmaceutical formulations. It may be used either alone or in combination with other parabens or with other antimicrobial agents. Owing to the poor solubility of the parabens, paraben salts (particularly the sodium salt) are more frequently used in formulations. However, this raises the $\mathrm{pH}$ of poorly buffered formulations.

Drug excipients interaction study by FTIR was carried out as per standard procedure. FTIR spectra of Diltiazem hydrochloride, HPMC K4M, sodium alginate, gellum gum and FTIR spectrum for physical mixture of Drug and polymers is shown in Figure 1. It was observed that principle peaks of drug were found to be in FTIR spectra of a drug as well as FTIR spectra of physical mixture of drug and excipients. It was suggested that there was no physical and chemical interaction between drug and polymers.

Drug excipient study was carried out by DSC spectra graph of a drug Diltiazem Hydrochloride and DSC spectra of drug and excipient was shown in Figure 2. It was observed that peak onset temperature and peak of 
temperature in DSC spectra of physical mixture of drug and polymers was compiled with DSC spectra behaviour as noted in DSC spectra of pure drug. Thus there was no physical and chemical interaction between drug and polymers.

Standard calibration of Diltiazem HCL was carried out in $0.1 \mathrm{~N} \mathrm{HCl}$ and result showed in Figure 3. From the standard curve, it was observed that the drug obeys Beer's law in concentration range of $2.0-20 \mu \mathrm{g} / \mathrm{ml}$ in 0.1 N HCL. Drug shown good linearity with regression of coefficient $\left(r^{2}=0.998\right)$ and equation for this line obtained was found to be $y=0.046 x+0.005$ which is used for the calculation of amount of drug and dissolution study.

In situ gel of formulation were characterized for various evaluation parameter such as $\mathrm{pH}$, lag time, total floating time, $\%$ drug content, viscosity before gel and viscosity after gel. The result of characterization of factorial batches was show in Table 4.

It was observed that $\mathrm{pH}$ of in situ gel of formulations (HPGG1 to HPGG9) were found to be range 7.2 to 7.4 . Viscosity before gel and after gel of in situ gel of formulation (HPGG1 to HPGG9) was found to be range $(9595 \pm 1.15)$ to $(32715 \pm 1.15) \mathrm{cp}$ and $(11253$ $\pm 1.73)$ to $(39850 \pm 1.73)$ cp respectively. It was observed that viscosity of in situ gels was dependent on concentration of Sodium alginate and ratio of polymer Gellum Gum and HPMC K4M. For Formulation, (HPGG1 to HPGG9), as concentration of sodium alginate was increased $(0.5 \%, 1 \%, 1.5 \%) \mathrm{w} / \mathrm{v}$, viscosity before gel and after gel was found to be also increased. For formulation, (HPGG1 TO HPGG3), as concentration gellum gum was decreases, and concentration of HPMC K4M increases, viscosity before gel and after gel was decreases. Similar observation was found for (HPGG4 to HPGG6) and (HPGG7 to HPGG9). In situ gel of formulation HPGG7 was shows highest viscosity i.e (32715 \pm 1.15$)$ cp which contain Sodium alginate $(1.5 \%)$ HPMC K4M $(0.5 \%)$ and Gellum gum $(1.5 \%)$ and HPGG3 was show lowest viscosity i.e. $(9595 \pm 1.15) \mathrm{cp}$ which contain sodium alginate $(0.5 \%)$, HPMC K4M (1.5\%) and gellum gum (0.5\%). Hence, it was concluded that viscosity of In situ gel formulation (HPGG1 to HPGG9) was contribute due to sodium alginate and ratio of Gellum Gum and HPMC K4M.

Lag Time of In situ gel of formulations (HPGG1 to HPGG9) were found to be range $(72 \pm 1.15)$ to $(98 \pm 0.57)$ sec. Here, it was observed that lag time of in situ gel depends on concentration of sodium alginate and ratio of Gellum gum and HPMC K4M. For Formulations (HPGG1 to HPGG9), as concentration of sodium alginatewereincreases $(0.5 \%, 1 \%, 1.5 \%) \mathrm{w} / \mathrm{v}$ respectively, Lag time of formulations were also increases. For formulations, (HPGG1 to HPGG3), as concentration gellum gum was decreases, and Concentration of HPMC K4M was Increases, lagtimeof formulations were decreases.Similar observation was found for (HPGG4 to HPGG6) and (HPGG7 to HPGG9). In situ gel of formulation HPGG7 was showed prolong lag time i.e. (98 \pm 0.57$) \mathrm{sec}$ which contain sodium alginate $(1.5 \%)$, HPMC K4M (0.5\%) and gellum gum (1.5\%) and also HPGG3 was showed minimum lag time i.e. $(72 \pm 1.15) \mathrm{sec}$ which contain sodium alginate $(0.5 \%)$, HPMC K4M $(1.5 \%)$ and gellum gum $(0.5 \%)$. Hence, it was concluded that viscosity of in situ gel formulations (HPGG1 to HPGG9) were contribute due to Sodium alginate and ratio of gellum gum and HPMC K4M. Here, an increase in the polymer concentration resulted in increases floating lag time of the prepared systems.

Total floating times of in situ gel of formulations (HPGG1 to HPGG9) were found to be more than 24 hours. All these formulation show good floating behaviour as dissolution media $0.1 \mathrm{~N}$ HCL came in contact with formulation, it become instantly gel due to reaction between sodium alginate and calcium alginate in presence of acidic medium. Simultaneously, gas generation was form due to reaction between tri sodium citrate and calcium carbonate. These gases was trapped in rigid structure of gel which has buoyant behaviour in dissolution media for prolong time sufficiently for up to 24 hours or more than 24 hours.

$\%$ Drug content of in situ gel of formulations (HPGG1 to HPGG9) was found to be range (98.14 \pm 1.073$)$ to $(99.92 \pm 0.04) \%$. Here, it was observed that drug content of in situ gel depends on concentration of Sodium alginate and ratio of gellum gum and HPMC K4M. For Formulations (HPGG1 to HPGG9), as concentration of sodium alginate $(0.5 \%, 1 \%, 1.5 \%)$ was increased, drug content of formulations were also increases. For formulations (HPGG1 to HPGG3) as concentration gellum gum was decreased and concentration of HPMC K4M was increases, drug content of formulations was decreases. Similar observations were found for (HPGG4 to HPGG6) and (HPGG7 to HPGG9). In situ gel of formulation HPGG7 was showed maximum drug content i.e. $(99.92 \pm 0.04) \%$ which contain sodium alginate $(1.5 \%)$ HPMC K4M $(0.5 \%)$ and gellum gum $(1.5 \%)$ and HPGG3 show minimum drug content i.e. $(98.14 \pm 1.073) \%$ which contain sodium alginate $(0.5 \%)$, HPMC K4M (1.5\%) and gellum gum (0.5\%).

The rheological properties of the solutions are of importance in view of their proposed oral administration. Result rheological behaviour of in situ gel formulations (HPGG1 to HPGG9) is shown in Figure 5. It was 
observed that shear rate was directly proportional to shear stress for both upward and downward curve. As evident from Figure 5 formulations (HPGG1 to HPGG9) shows slight decrease in viscosity with increase in rpm due to the shear thinning behaviour. Though there was a shear thinning pattern observed, there was a fair resistance to flow as far as pour ability of the sol was concerned. This is mainly attributed to high polymer concentration. These formulations show better flow and good sol properties. Hence, in situ gels formulations (HPGG1 to HPGG9) shows peudoplastic Flow.

Cumulative drug release of factorial batches of in situ gels was shown in Table 5 and Figure 4. In vitro drug release of in situ gels of formulations (HPGG1 to HPGG9) was found to be range (79.2 \pm 0.50$) \%$ to $(96.61 \pm 0.50) \%$ up to $24 \mathrm{hr}$. Here, it was observed that cumulative drug release of in situ gels depends on concentration of sodium alginate and ratio of gellum gum and HPMC K4M. For formulations (HPGG1 to HPGG9), as concentration of sodium alginate $(0.5 \%, 1 \%, 1.5 \%)$ was increased, cumulative drug release of formulations decreases. For formulations, (HPGG1 to HPGG3), as concentration gellum gum decreases, and concentration of HPMC K4M increases, cumulative drug release of formulations were increases. Similar observations were found for (HPGG4 to HPGG6) and (HPGG7 to HPGG9). In situ gels of formulation HPGG7 was show prolong and controlled cumulative drug release i.e. (79.2 \pm $0.50) \%$ up to $24 \mathrm{hr}$ which contain sodium alginate $(1.5 \%)$, HPMC K4M (0.5\%) and gellum gum $(1.5 \%)$; HPGG3 was show $\%$ cumulative drug release i.e. (96.61 $\pm 0.50) \%$ up to $24 \mathrm{hr}$ which contain sodium alginate $(0.5 \%)$, HPMC K4M (1.5\%) and gellum gum (0.5\%).

Hence, it was concluded that $\%$ cumulative drug release of in situ gels formulations (HPGG1 to HPGG9) were contribute due to sodium alginate and ratio of gellum gum and HPMC K4M.

The release kinetic of drug release was shown in Table 6 . It was observed that in situ gels formulations (HPGG1, HPGG2, HPGG4, HPGG5, and HPGG6) were best fitted to peppas model. In situ gels formulation HPGG2 were $\mathrm{r}^{2}$ value (0.9823) and $\mathrm{n}$ value (0.5283). In situ gels formulation HPGG3 was best fitted to first order release with $\mathrm{r}^{2}$ value (0.9843), $\mathrm{n}$ value (0.4866). In situ gels formulations (HPGG7, HPGG8, and HPGG9) were best fitted to matrix model. Formulation HPGG7 has $\mathrm{r}^{2}$ value 0.9738 and n value (0.6397). From evaluation of in situ gels formulation for factorial batches, formulation HPGG7 has show good gel strength, lag time $(98 \pm 0.57)$ sec, ph value $(7.4 \pm 0.20), \%$ drug release $(99.92 \pm 0.04) \%$, viscosity before and after gel (32715 \pm 1.15$)$ and $(39850$ \pm 1.73 ) cp respectively, total floating time more than 24 hours and also have good controlled release behaviour as it retard drug release up to $(79.2 \pm 0.50) \%$. Hence, from above it was concluded that formulation, in situ gels formulation HPPGG7 containing sodium alginate (1.5\%), HPMC K4M (0.5\%), gellum gum (1.5\%), which could be most promising gastro-retentive in situ gel formulation.

The stability studies of optimum formulation HPGG7 revealed that there is slightly reduction in drug content was observed over period of 3 month. No significant change was observed on $\%$ drug content, $\mathrm{pH}$, lag time, total floating time, viscosity before and after gel, $\%$ cumulative drug release (after 24 hours) at various storing condition $10^{\circ} \mathrm{C} \pm 2^{\circ} \mathrm{C}, 75 \% \pm 5 \% \mathrm{RH}, 25^{\circ} \mathrm{C} \pm$ $2^{\circ} \mathrm{C}, 75 \% \pm 5 \% \mathrm{RH}$ and $40^{\circ} \mathrm{C} \pm 2{ }^{\circ} \mathrm{C}, 75 \% \pm 5 \% \mathrm{RH}$. Hence formulation, HPGG7 was found to be stable for 3 month. The results are shown in Table 7.

\section{CONCLUSION}

It was concluded that In situ gel formulation HPPGG7 containing sodium alginate (1.5\%), HPMC K4M (0.5\%), Gellum gum (1.5\%), which could be most promising gastro-retentive in situ gel formulation. In situ gel will remain stomach for prolong time up to 24 hours and during time it release in controlled manner. In situ gel will be promising pharmaceutical formulation for development of gastro-retentive drug delivery system for Diltiazem HCL.

\section{ACKNOWLGEMENT}

Author like to thank Pellet Pharma, Hydyabad for providing Diltiazem $\mathrm{HCl}$ for present research work.

\section{CONFLICT OF INTEREST}

Authors have no conflict of interest to declare.

\section{ABBREVIATION USED}

HPMC: Hydroxyl Propyl Methyl Cellulose; DSC: Differential Scanning Calorimeter.

\section{REFERENCES}

1. Darandale, Sharad S and Pradeep Vavia R. Design of a gastro retentive mucoadhesive dosage form of furosemide for controlled release. Acta Pharmaceutica Sinica B. 2012;2(5):509-17.

2. Özdemir, Nurten, Sefika Ordu, and Yalçin Özkan. Studies of floating dosage forms of furosemide: in vitro and in vivo evaluations of bilayer Tablet formulations. Drug Development and Industrial Pharmacy. 2000:26(8):857-66.

3. Debnath and Subhashis et al. Formulation and evaluation of floatable in situ gel as carrier for stomach-specific drug delivery of metaclopramide HCl. International Journal of Pharmaceutical Research. 2011;1(1):53-6.

4. Chawla, Garima and Bansal A. A means to address regional variability in intestinal drug absorption. Pharm Tech. 2003;27:50-68. 
5. Davis and Stanley S. Formulation strategies for absorption windows. Drug Discovery Today. 2005;10(4):249-57.

6. Arora and Shweta et al. Floating drug delivery systems: a review. Aaps Pharm Sci Tech. 2005;6(3):E372-90.

7. Gutierrez-Rocca, Jose, Hossein Omidian and Khalid Shah. Progresses in Gastro Retentive Drug Delivery Systems. 2004;152-6.

8. Talukdar MM, et al. In vivo evaluation of xanthan gum as a potential excipient for oral controlled-release matrix Tablet formulation. International Journal of Pharmaceutics. 1998;169(1):105-13.

9. Choi BY, et al. Preparation of alginate beads for floating drug delivery system: effects of $\mathrm{CO}_{2}$ gas-forming agents. International Journal of Pharmaceutics. 2002;239(1):81-91.

10. Sungthongjeen, Srisagul, et al. Preparation and in vitro evaluation of a multiple-unit floating drug delivery system based on gas formation technique. International Journal of Pharmaceutics. 2006;324(2):136-43.

11. Shimpi, Shyam, et al. Preparation and evaluation of diltiazem hydrochlorideGelucire $43 / 01$ floating granules prepared by melt granulation. AAPS Pharm Sci Tech. 2004;5(3):51-6.

12. Tanwar YS, et al. Floating microspheres: development, characterization and applications. Pharmainfo Net. 2006;4(3):242-51.

13. Jaimini M, Rana AC and Tanwar YS. Formulation and evaluation of famotidine floating tablets. Cur Drug Dev. 2007;4:51-5.

14. Bobade, Nishan N, et al. Formulation and Evaluation of Controlled Release Gastro-Retentive Muco-Adhesive Microspheres For Diltiazem Hydrochloride. Indo American Journal of Pharmaceutical Research.2016;6(1):4153-65.

15. Ali J, Arora S, Ahuja S, Babbar A, Sharma R, Khar R et al. Formulation and development of hydro dynamically balanced system for metformin: in vitro and in vivo evaluation. Eur J Pharm Biopharm. 2007;67:196-201.

16. Panigrahy Rabi N, Arun M, Mahale, and Pushpendra S. Dhaked. Formulation and In vitro Evaluation of Combined Floating mucoadesive Tablet of Metoprolol Succinate. International Journal of Pharmacy and Pharmaceutical Sciences. 2011;3(2):221-6.

17. Sivanarayana, V, Kishore SP, and Kumar J. Effect of cross linking agent and polymer on the characteristics of Diltiazem $\mathrm{HCl}$ loaded muco adhesive microsphere. American Journal of Pharmatech Research. 2012;2(1):398-410.

18. Kulkarni, Abhijeet D, Deepak Bari B, Sanjay Surana J and Chandrakantsing V. Pardeshi. In vitro, ex vivo and in vivo performance of chitosan-based spray-dried nasal muco adhesive microspheres of diltiazem hydrochloride. Journal of Drug Delivery Science and Technology. 2016;31:108-17.

19. Das, Malay K and Divya P. Maurya. Evaluation of diltiazem hydrochlorideloaded mucoadhesive microspheres prepared by emulsification-internal gelation technique. Acta Pol Pharm. 2008;65(2):249-59.

20. Ur-Rehman, Tofeeq, Staffan Tavelin, and Gerhard Gröbner. Chitosan in situ gelation for improved drug loading and retention in poloxamer 407 gels. International Journal of Pharmaceutics. 2011;409(1):19-29.

21. Alhamdany, Anas Tarik Nafei, Nidhal Khazaal Maraie, and Bahir Abd Razzaq Alkinani. "UK Journal of Pharmaceutical and Biosciences Available at www. ukjpb. com."
22. Subhashis, Debnath, et al. Formulation and evaluation of floa Table In-situ gel as carrier for stomach-specific drug delivery of metoclopramide hcl. Int. Journal of Pharm Frontier Research. 2011;1(1):53-64.

23. Chaniyara, Sanket, et al. Formulation \& Evaluation of Floatable In situ Gel for Stomach-specific Drug Delivery of Ofloxacin. American Journal of Advanced Drug Delivery. 2013;1(3):285-99.

24. Vipul, Vora and Biswajit Basu. Formulation and characterization of novel floating in-situ gelling system for controlled delivery of ramipril. International Journal of Drug Delivery. 2013;5(1):43-5.

25. Bobade, Nishan N., et al. Development and characterization of cyclodextrin derivatives inclusion complex of ezetimibe for fast dissolution Tablets. Indo American Journal of Pharmaceutical Research. 2015;5(10):3093-106.

26. Bobade, Nishan N and Ashish K. Khrobragade, Jaymin M. Patel, Shrikant D. Pande, and Shagufta A. Khan. Design and In vitro Characterization of Novel Phase Transition Systems For Nasal Drug Delivery. (2015).

27. Patel, Miteshkumar J., et al. Strategy for development of $\mathrm{pH}$ triggered floating in-situ gel of Levetiracetam. Am J Pharm Tech Res. 2012;2(3):828-41.

28. Patel RP, Dadhani B, Ladani R, Baria AH and Jigar Patel. Formulation, evaluation and optimization of stomach specific in situ gel of clarithromycin and metronidazole benzoate. International Journal of Drug Delivery. 2010;2(2):141-53.

29. Gulecha BS, Shahi S and Lahoti SR. Floating in situ Gelling Drug Delivery System of Verapamil Hydrochloride. American Journal of Pharm Tech Research. 2012;2(4):954-69.

30. Abd EL, Gawad HA, Esmail MR, Osama AS and Rehab MY. Formulation and in-vivo study of diltiazem hydrochloride tablets prepared using inter polymer complexes. British J Pharm Res. 2012;2(1):17-40.

31. Jivani, Rishad R, Chhagan Patel N, Dashrath Patel M and Nurudin P Jivani. Development of a novel floating in situ gelling system for stomach specific drug delivery of the narrow absorption window drug baclofen. Iranian Journal of Pharmaceutical Research. 2010;359-68.

32. Shivaraju SP, and Senthilkumar SK. Preparation and evaluation of ornidazole In situ gelling system for gastro retentive drug delivery. International Journal of Pharmacy. 2013;3(2):62-9.

33. Zatz JL, and Woodford DW. Prolonged release of theophylline from aqueous suspensions. Drug Development and Industrial Pharmacy. 1987;13(12):2159-78.

34. Bandana, Singh, Kanoujia Jovita and Pandey Manisha. Formulation and evaluation of floating microspheres of famotidine. Metabolism. 2010;4(3).

35. Dash, Suvakanta, et al. Kinetic modeling on drug release from controlled drug delivery systems. Acta Pol Pharm. 2010;67(3):217-23.

36. Lachman L, Lieberman HA, and Kanig JL. Kinetic Principles And Stability. Theory And Practice of Industrial Pharmacy. Varghese Publishing House. $3^{\text {rd }}$ Ed. Philadelphia. 1986;760-803.

37. Guideline, $\mathrm{ICH}$ Harmonised Tripartite. Stability testing of new drug substances and products. Q1A (R2), Current Step 4. 2003.

\section{SUMMARY}

- Drug and Polymer Compatibility Studies was revealed that there is no physicochemical interaction between drug and polymer under study.

- Floating lag time and floating time was dependent on concentration of sodium alginate and polymer ratio (gellum gum/HPMC K4M).

- From cumulative drug release of drug, it was concluded that high concentration gellum gum, sodium alginate was responsible for controlled release behavior.

- Viscosity of formulation was dependent on all polymers under study. It was also noted that polymer HPMC K4M maintain flow-ability of formulation.

- All formulations were showed pseudo-plastic behaviour.

- Kinetic data of release study was concluded that high polymer concentration formulation shows matrix release pattern of drug release.

- Stability data of optimized formulation was remark that that is no significant change in drug for short turn and also there are no changes was found in floating and rheological behaviours of study. 